\title{
The Impact of the First Wave of the COVID-19 Pandemic on Patients' Perceptions of Chronic Pain
}

\author{
Maria Eleni Smyrnioti ${ }^{\prime}$ \\ Georgios Lyrakos ${ }^{2}$ \\ Maria Meindani' \\ Paraskevi Matsota' \\ Georgia Kostopanagiotou' \\ Chrysanthi Batistaki ${ }^{1}$
}

'2nd Department of Anaesthesiology, School of Medicine, National and Kapodistrian University of Athens, Pain Management Unit, Attikon Hospital, Athens, Greece; ${ }^{2}$ Psychiatric Ward and Thalassaemia Transfusion Unit, General Hospital of Nikaia, Piraeus, Greece
Correspondence: Maria Eleni Smyrnioti 2nd Department of Anaesthesiology, School of Medicine, National and Kapodistrian University of Athens, Pain Management Unit, Attikon Hospital, I Rimini str, Athens, I2462, Greece

Tel +306947526444

Fax +30210583237।

Email marilena_smyrnioti@yahoo.gr

\begin{abstract}
Purpose: On 10 March 2020, Greece entered an increasingly restrictive 42-day lockdown, in order to contain the first wave of the COVID-19 pandemic. All scheduled appointments and activities of the pain clinics around the country were postponed indefinitely. The aim of this prospective study was to assess the perceived impact of the first wave of the pandemic on pain, quality of life, and access to treatment, during the first austere lockdown in Greece. Patients and Methods: In this cross-sectional study, 101 patients suffering from chronic pain completed a structured questionnaire. Levels of depression, anxiety, stress, personal wellbeing, optimism and personality traits were also evaluated, using the Depression, Anxiety and Stress Scale (DASS42), the Ten Item Personality Index (TIPI), the Life Orientation Test-Revised (GrLOT-R) and the Personal Wellbeing Index (PWI).

Results: Despite the dramatic decrease in health care visitations before, during and after the imposed lockdown, most patients did not feel that access to pain physicians and medication was significantly affected. Higher levels of stress, anxiety, depression, neuroticism, openness to experience and general satisfaction with life seemed to be important determinant factors in how patients experienced their level, intensity and duration of pain, quality of life and response to medication.

Conclusion: The effects of the lockdown had a more severe impact on patients than the pandemic itself. For most, the level of their pain was not affected by the pandemic and was affected only slightly by the lockdown. Quality of life, however, was affected formost participants. Both the necessity and the complications of introducing the use of telemedicine to Greek chronic pain patients became evident during the study.
\end{abstract}

Keywords: COVID-19 psychosocial implications, quality of life, healthcare access, telemedicine

\section{Introduction}

The COVID-19 pandemic is the largest, most severe global public health crisis the world has faced since the 1918 influenza pandemic. Coronavirus disease 2019, also known as severe acute respiratory syndrome coronavirus 2 (SARSCoV-2) emerged in Wuhan, China, in December 2019. Symptoms include pharyngodynia, dry cough, fever, possible loss of taste and smell, and difficulty in breathing. $8-15 \%$ of patients are estimated to develop severe symptoms including respiratory failure, acute respiratory distress syndrome (ARDS), and multiple organ failure, requiring intensive care unit admission and ventilatory support. Among the patients admitted to the Intensive Care Unit (ICU), mortality ranges from $<14 \%$ to $>66 \%$, depending on patient-specific factors and underlying comorbid conditions. ${ }^{1,2}$ 
Chronic pain is one of the most common disorders and one of the leading reasons for seeking medical care. Approximately $20 \%$ of people worldwide are affected by chronic or recurring pain. ${ }^{3}$ Chronic pain conditions typically affect the older population, they are mostly musculoskeletal in nature ${ }^{4}$ and often co-exist with other comorbidities, predominantly coronary artery disease, diabetes, cancer and chronic obstructive pulmonary disease (COPD). ${ }^{5,6}$ They have debilitating effects on patients' personal and professional lives, subsequent social and financial implications, and significant costs to healthcare services, benefit agencies, and country economies. ${ }^{7}$ Some of the core issues in the successful management of chronic pain patients include (a) addressing concurrent mental health issues that include depression, anxiety, hopelessness, and negative thoughts, ${ }^{4,8,9}$ (b) maintaining a certain level of social and physical activity $^{4,10,11}$ and (c) guaranteeing security and continuity in primary care, which includes feelings of coherence, confidence in and accessibility to care. ${ }^{12}$

The relationship between depression, anxiety and chronic pain is paramount in understanding and handling chronic pain patients, and seems to be bi-directional. Patients with higher depression and anxiety levels experience pain as more intense and more disabling. ${ }^{13,14}$ Chronic pain significantly predicts the onset of depressive episodes, while depression significantly predicts the onset of new chronic pain symptoms and other medical conditions. ${ }^{15}$ In addition to being mediating factors in the course and prognosis of pain, depression, anxiety and psychological comorbidity are significantly associated with response and adherence to treatment ${ }^{16}$ and medication misuse. ${ }^{17,18}$

On 26th February 2020, the first Covid-19 case in Greece was confirmed. "Attikon" University Hospital was immediately assigned as the main tertiary reference hospital for the treatment of Covid-19 cases. ${ }^{19}$ On March 10th, Greece entered an increasingly restrictive lockdown to contain this first wave of the pandemic. On May 4th, the government gradually began to lift restrictions on movement and to restart business activities. For 42 days, all scheduled appointments and activities for health services around the country were put on hold and became inaccessible to the public. Approximately 450500 prescheduled appointments of patients visiting the Pain Clinic regularly for follow-up, prescription or interventional treatment, were postponed indefinitely.

Based on the impact of recent socioeconomic crises on chronic pain patients, ${ }^{20}$ on the impact of previous pandemics on public health, ${ }^{21,22}$ on the lessons learned from China in the management of chronic pain patients during the Covid-19 pandemic, ${ }^{23}$ and on the bi-directional relationship between psychological comorbidities and chronic pain, ${ }^{13-18}$ an association was expected between the pandemic, the subsequent lockdown, the psychological sequelae, and pain. In the present study, we wished to examine the psychological impact of the Covid-19 pandemic on patients suffering from chronic pain, in a country that is already impaired from a decade of recession. More precisely, we wished to examine the perceived effect of the pandemic and lockdown on patients' intensity and characteristics of pain, access to medical care and medication, psychological distress, and quality of life during the first wave of Covid-19 disease in Greece.

\section{Patients and Methods}

This study took place at the Pain Management Unit of Attikon University Hospital, shortly after the initial break of the Covid-19 pandemic, during the first austere lockdown in Greece, from March 10th to May 15th. We employed a descriptive cross-sectional study design, using a convenience sample. ${ }^{24-27}$ Taking into consideration the limited time frame of this study, we calculated a sample size that would allow us to use parametric statistics. Research proposal was approved by the Committee of Bioethics and Deontology, University Hospital "Attikon" (232/11-05-2020) and is conducted in accordance with the Declaration of Helsinki.

One hundred and one outpatients suffering from chronic malignant and non-malignant pain participated in the study. All patients with a prescheduled appointment at the Pain Clinic during the above-mentioned period were contacted via phone due to the austere lockdown, were informed about the purpose of the study, and were asked to participate. The response rate was $77.2 \%$. Data were collected using Google Forms $(\mathrm{N}=38)$ and via phone interview by one of the psychologists of the Pain Management Unit $(\mathrm{N}=48)$, based on each participant's preference and ability. A few patients only actually visited the Pain Clinic (as emergencies) during the course of this study and were thus able to fill in the questionnaires in paper format $(\mathrm{N}=15)$. Inclusion criteria were: age $>18$ years old, ability to read and write in Greek, and length of pain treatment at the Pain Unit of more than 3 months. All patients provided informed consent. Participation in the study was voluntary, and confidentiality was maintained for all participants. 
The impact of the pandemic on pain, pain management and patients' quality of life was evaluated with a custom, structured questionnaire that was created by the pain management team, which included two anaesthesiologists (pain physicians) and two psychologists with long clinical involvement in the care of patients with chronic pain. The questionnaire was developed based on the one used and validated in a previous study by the same team to assess the impact of the economic crisis on chronic pain patients. ${ }^{20,28}$ It was further modified to assess the new problems that accompany the Covid-19 pandemic and subsequent lockdown. The questionnaire has two parts. The first part includes items on patients' demographic characteristics, occupation, marital status, number of residents per household, as well as questions regarding health status and a Numeric Rating Scale (NRS) to measure pain intensity (Figure S1). The second part consists of 26 questions developed to assess patients' perceptions on the impact of the Covid-19 pandemic and subsequent lockdown on pain intensity and duration, patients' quality of life and patients' access to treatment and medication. Most of the items include three response options: (1) a lot, (2) moderately, and (3) not at all (Figure $\underline{\text { S2). }}$. Cronbach's $\alpha$, for the 15 questions that concern the effect of the pandemic in patients with chronic pain is 0.797 and the Cronbach's Alpha Based on Standardized Items is 0.801 (Table 1). Additionally, the following assessment tools, translated and validated in Greek, were used for psychological evaluation: (a) Depression, Anxiety and Stress Scale (DASS42), (b) Ten Item Personality Index (TIPI), (c) Life Orientation Test-Revised (GrLOT-R) and (d) Personal Wellbeing Index (PWI). The intensity of pain was measured with the Numeric Rating Scale (NRS 010). ${ }^{29-32}$

One-Way Analysis of variance was applied to explore significant differences between the questions exploring the effect of the pandemic in pain patients and the questionnaires that were used to measure depression, anxiety and stress (DASS), optimism (LOT-R), personal well-being (PWI) and personality type (TIPI). All data were analyzed with SPSS 24 for Windows.

\section{Results}

\section{Demographic Characteristics}

The patients who participated in this study were mostly women, urban residents, married or widowed. Almost half of our sample were retired or household-occupied. The age of the participants varied from 18 to 88 years old, with a mean of 58.5. The majority of patients suffered from non-malignant pain, and predominantly musculoskeletal pain (43.6\%) and headache (29.7\%) (Tables 2 and 3). $66.3 \%$ of the participants suffered from at least one other comorbid condition in addition to chronic pain, with cardio-vascular diseases (39.7\%) being the most prominent.

\section{Access to Care and Visits to the Hospital}

The main reason for initially visiting the Pain Management Unit prior to the Covid-19 pandemic, was a scheduled appointment for follow-up (48.5\%) or for interventional treatment $(23.8 \%)$. The reason for visiting the Pain Unit was consistent with the frequency of visits: $45.5 \%$ of the participants would visit 2-3 times per year, $28.7 \%$ would make more than 3 visits per year and $19.8 \%$ of the participants were new patients, having visited the Pain Unit only once prior to the pandemic. Most of the patients $(60 \%)$ had to decrease their visits to the pain clinic at the time of assessment, and for approximately $72 \%$ of the participants, the number of visits to other health services was also affected, moderately or significantly.

\section{Level of Pain, Accessibility to Physicians and Medication}

Regarding the questions "Did the Covid-19 pandemic affect your pain levels?" and " ... your treatment in general?", our results showed that $>50 \%$ of patients did not feel significantly affected. Specifically, $69.3 \%$ felt their pain physicians would be accessible via phone, and $84.2 \%$ were confident they would have ongoing access to medication despite the circumstances. Regarding pain, $33.7 \%$ reported that their pain levels were affected by the pandemic itself moderately or significantly, and $40.6 \%$ of patients were affected specifically by the situation of "lockdown" moderately or significantly (Table 4).

Regarding the question "Did the restrictive measures (lockdown) affect your pain levels?", one-way between subjects ANOVA analysis revealed significant differences in stress $[\mathrm{F}(2,98)=12.134, \mathrm{p}=0.001]$, anxiety $[\mathrm{F}(2,98)=8.869$, $\mathrm{p}=0.001]$ and depression $[\mathrm{F}(2,98)=6.927, \mathrm{p}=0.002]$, as well as in emotional stability/neuroticism $[\mathrm{F}(2,98)=3.984$, $\mathrm{p}=0.022]$ in patients affected by the lockdown. After the application of Bonferroni criterion, the difference in stress was significant between those that their pain levels had been affected a lot and the other two groups, moderately and not at all (Mean Differences were 11.10 and $14.600 \mathrm{p}=0.004$ and 0.001 respectively). This effect was also noticed in anxiety 


\begin{tabular}{|c|c|c|c|c|c|c|c|c|c|c|c|c|c|c|c|}
\hline 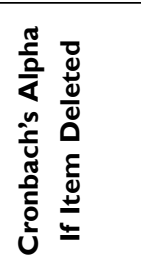 & $\begin{array}{l}\infty \\
\stackrel{0}{0} \\
\stackrel{8}{8}\end{array}$ & $\begin{array}{l}\stackrel{R}{i} \\
\stackrel{8}{8}\end{array}$ & $\begin{array}{l}\stackrel{\infty}{0} \\
\stackrel{8}{8}\end{array}$ & $\begin{array}{l}\frac{2}{2} \\
\stackrel{8}{8}\end{array}$ & $\begin{array}{l}\overline{0} \\
\stackrel{8}{8}\end{array}$ & $\begin{array}{l}\stackrel{\infty}{\hat{~}} \\
\stackrel{8}{8}\end{array}$ & $\begin{array}{l}\hat{\text { o }} \\
\stackrel{0}{0}\end{array}$ & 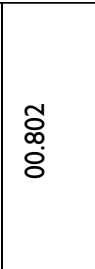 & 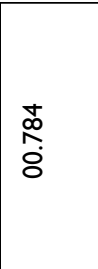 & 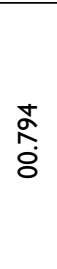 & $\begin{array}{l}\hat{\kappa} \\
\stackrel{8}{8}\end{array}$ & $\begin{array}{l}\stackrel{0}{8} \\
\stackrel{8}{8}\end{array}$ & $\begin{array}{l}\stackrel{\infty}{2} \\
\stackrel{8}{8}\end{array}$ & $\begin{array}{l}\stackrel{+}{\infty} \\
\stackrel{8}{8}\end{array}$ & $\begin{array}{l}\frac{0}{\infty} \\
\stackrel{8}{8}\end{array}$ \\
\hline 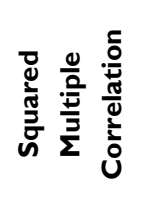 & $\begin{array}{l}m \\
\hat{o} \\
o \\
o\end{array}$ & 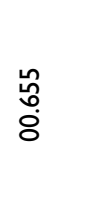 & $\begin{array}{l}\bar{n} \\
\stackrel{0}{8} \\
\stackrel{8}{0}\end{array}$ & $\begin{array}{l}\text { น̊ํ } \\
\hat{\leftrightarrow} \\
8\end{array}$ & $\begin{array}{l}\mathscr{0}_{0}^{0} \\
\stackrel{8}{0}\end{array}$ & $\begin{array}{l}\stackrel{a}{\rho} \\
\stackrel{\rho}{8}\end{array}$ & $\frac{n}{T}$ & $\frac{\pi}{\overline{8}}$ & $\begin{array}{l}\tilde{o} \\
\dot{f} \\
8\end{array}$ & $\begin{array}{l}\text { م્ત } \\
\text { هั }\end{array}$ & $\begin{array}{l}\stackrel{8}{0} \\
\stackrel{8}{8}\end{array}$ & $\begin{array}{l}\text { 岕 } \\
\text { ¿ }\end{array}$ & 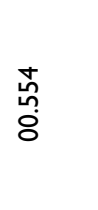 & $\begin{array}{l}\stackrel{0}{\infty} \\
\stackrel{0}{0} \\
\stackrel{8}{8}\end{array}$ & $\frac{20}{8}$ \\
\hline 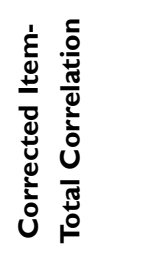 & 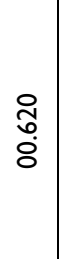 & $\begin{array}{l}\hat{\imath} \\
\hat{n} \\
8\end{array}$ & $\begin{array}{l}\text { 色 } \\
\stackrel{8}{8}\end{array}$ & $\begin{array}{l}\stackrel{\infty}{0} \\
\stackrel{\leftrightarrow}{0}\end{array}$ & $\begin{array}{l}\bar{n} \\
\text { ¿̊ }\end{array}$ & \begin{tabular}{l}
\multirow{\alpha}{\sigma}{} \\
$\stackrel{8}{8}$
\end{tabular} & $\frac{\bar{\infty}}{\overline{8}}$ & $\overline{\overline{8}}$ & $\begin{array}{l}\bar{f} \\
\dot{8}\end{array}$ & 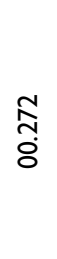 & 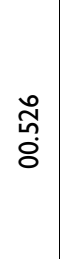 & $\frac{\sim}{n}$ & $\frac{\frac{m}{\omega n}}{8}$ & 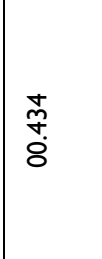 & $\begin{array}{l}\infty \\
0 \\
\end{array}$ \\
\hline 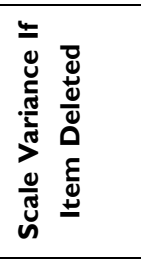 & 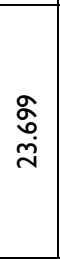 & 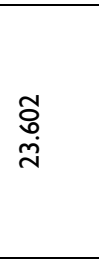 & $\begin{array}{l}\text { స్ } \\
\text { ָू }\end{array}$ & $\begin{array}{l}\tilde{\sigma} \\
\underset{\sim}{\sim}\end{array}$ & $\begin{array}{l}\text { ㅇ. } \\
\text { ํ. }\end{array}$ & $\begin{array}{l}\underset{\tilde{J}}{\mathrm{~J}} \\
\dot{\sim}\end{array}$ & 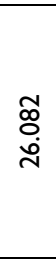 & $\begin{array}{l}\underset{n}{n} \\
\stackrel{\sim}{\sim}\end{array}$ & $\begin{array}{l}\text { مू } \\
\text { ஸे }\end{array}$ & 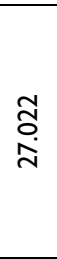 & $\begin{array}{l}\stackrel{m}{\curvearrowright} \\
\underset{\sim}{\sim}\end{array}$ & $\frac{\frac{O}{d}}{\dot{d}}$ & 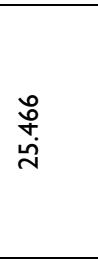 & 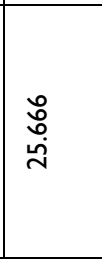 & $\begin{array}{l}\widehat{o} \\
\stackrel{\infty}{\infty} \\
\stackrel{\sim}{d}\end{array}$ \\
\hline 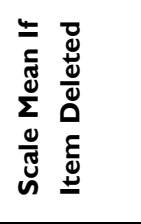 & $\begin{array}{l}\frac{a}{\omega} \\
\stackrel{\sim}{\sim}\end{array}$ & $\underset{\stackrel{\sim}{\sim}}{\stackrel{\sim}{\sim}}$ & $\begin{array}{l}\text { 애 } \\
\sigma \\
o \\
o \\
\sim\end{array}$ & 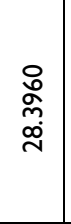 & 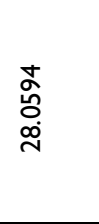 & $\begin{array}{l}\text { ơ } \\
\text { o } \\
\text { i }\end{array}$ & $\begin{array}{l}\stackrel{\circ}{\circ} \\
\stackrel{\circ}{\infty} \\
\stackrel{\infty}{\infty}\end{array}$ & $\begin{array}{l}\stackrel{+}{\circ} \\
\stackrel{\sim}{N} \\
\stackrel{N}{~}\end{array}$ & 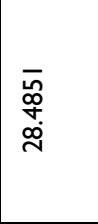 & $\begin{array}{l}\text { ᄋ } \\
\stackrel{\circ}{\infty} \\
\stackrel{\infty}{\infty}\end{array}$ & 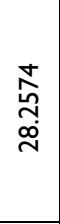 & 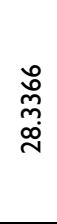 & $\begin{array}{l}\stackrel{\circ}{\circ} \\
\underset{\sim}{\infty} \\
\stackrel{\sim}{\infty}\end{array}$ & 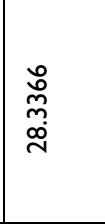 & 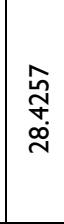 \\
\hline 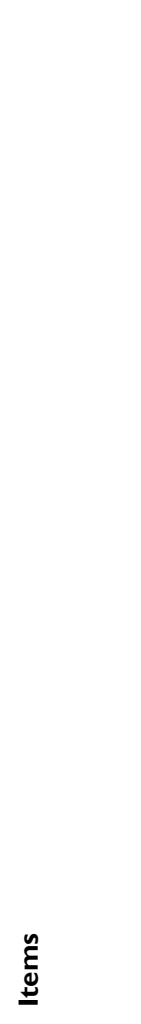 & 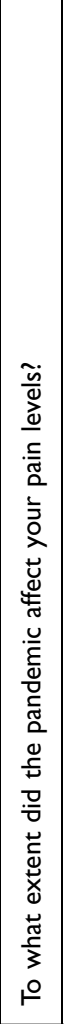 & 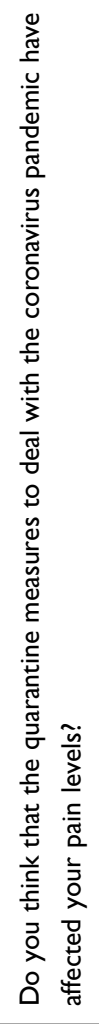 & 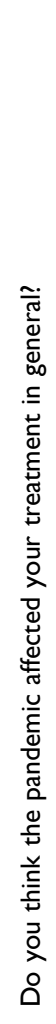 & 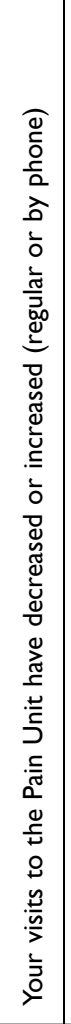 & 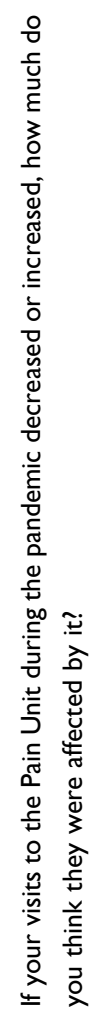 & 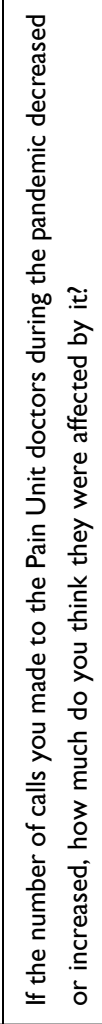 & 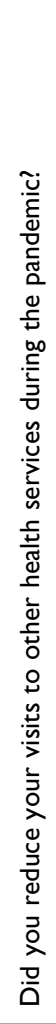 & 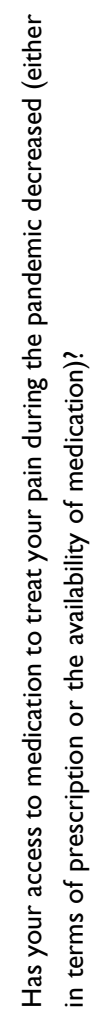 & 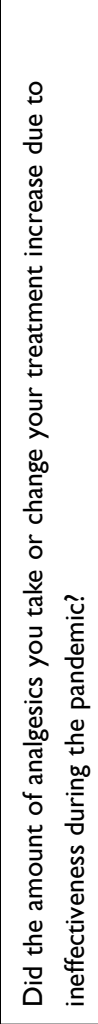 & 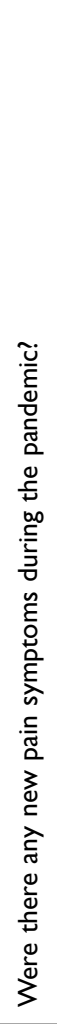 & 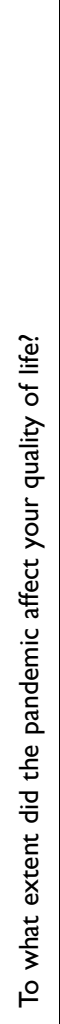 & 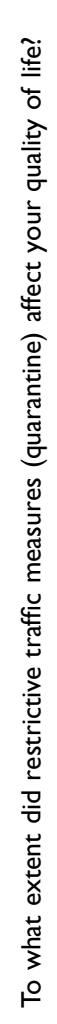 & 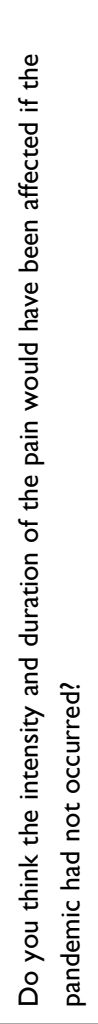 & 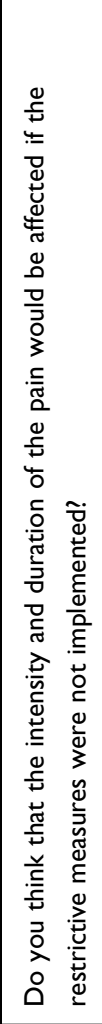 & 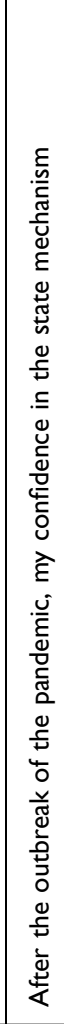 \\
\hline
\end{tabular}


Table 2 Demographic Characteristics of the Patients Participating in the Study

\begin{tabular}{|c|c|c|}
\hline & $N=10 \mid$ & $\%$ \\
\hline \multicolumn{3}{|l|}{ Age } \\
\hline Male & 17 & 16.8 \\
\hline Female & 84 & 83.2 \\
\hline \multicolumn{3}{|l|}{ Occupation } \\
\hline Public sector & 15 & 14.9 \\
\hline Private sector & 9 & 8.9 \\
\hline Freelance & 6 & 5.9 \\
\hline Retired & 40 & 39.6 \\
\hline Household occupied & 12 & 11.9 \\
\hline Disability retirement & 7 & 6.9 \\
\hline Unemployed & 10 & 9.9 \\
\hline Other & 2 & 2.0 \\
\hline \multicolumn{3}{|l|}{ Marital status } \\
\hline Single & 9 & 8.9 \\
\hline In a relationship & 9 & 8.9 \\
\hline Married & 58 & 57.4 \\
\hline Divorced & 6 & 5.9 \\
\hline Widowed & 19 & 18.8 \\
\hline \multicolumn{3}{|l|}{ Main cause of pain } \\
\hline Headache & 30 & 29.7 \\
\hline Musculoskeletal pain & 44 & 43.6 \\
\hline Neuropathic pain & 10 & 9.9 \\
\hline Visceral pain & 1 & 1.0 \\
\hline Cancer pain & 1 & 1.0 \\
\hline $\begin{array}{l}\text { Chronic post- } \\
\text { traumatic pain }\end{array}$ & 3 & 3.0 \\
\hline Mixed pain & 12 & 11.9 \\
\hline
\end{tabular}

with significant differences between those that their pain levels had been affected a lot and the other two groups, moderately and not at all (Mean Differences were 9.340 and $9.616 \mathrm{p}=0.002$ and 0.001 respectively). The same result was found in depression as well, with significant differences between those that their pain levels had been affected a lot with the other two groups, moderately and not at all (Mean Differences were 8.700 and $11.583 \mathrm{p}=0.048$ and 0.001 ), respectively. In neuroticism, significant differences were revealed between those that had been affected a lot and those that had not been affected at all (Mean difference $=1.816, \mathrm{p}=0.043$ ).

\section{Intensity and Duration of Pain}

$23.8 \%$ of the participants reported that their personal experience of pain intensity and duration would be better if it was not for the pandemic, and $25.7 \%$ if it was not for
Table 3 Descriptive Variables: Age, Children, Days Since Lockdown, Pain, Stress, Anxiety, Depression, Optimism, Extraversion, Conscientiousness, Agreeableness, Neuroticism, Openness to Experience, Satisfaction with Life

\begin{tabular}{|c|c|c|c|c|c|}
\hline & $\mathbf{N}$ & Min & Max & Mean & SD \\
\hline Age & 101 & 17.00 & 88.00 & 58.5941 & 16.15746 \\
\hline Children & 101 & 00.00 & 4.00 & 1.5050 & 1.00622 \\
\hline $\begin{array}{l}\text { How many people } \\
\text { live in the household }\end{array}$ & 101 & 00.00 & 11.00 & 2.3564 & 1.41127 \\
\hline $\begin{array}{l}\text { Days since Covid-19 } \\
\text { lockdown }\end{array}$ & 101 & 40.00 & 98.00 & 61.5743 & 16.22982 \\
\hline Pain intensity (NRS) & 101 & 00.00 & 10.00 & 4.5941 & 3.29296 \\
\hline \multicolumn{6}{|c|}{ Depression Anxiety Stress Scale 42 (DASS42) } \\
\hline Stress & 101 & 00.00 & 42.00 & 16.0792 & II .65477 \\
\hline Anxiety & 101 & 00.00 & 42.00 & 9.4752 & 8.94270 \\
\hline Depression & 101 & 00.00 & 42.00 & 13.4653 & 11.71031 \\
\hline \multicolumn{6}{|c|}{ Life Orientation Test - Revised (LOT-R) } \\
\hline Total lot & 101 & 00.00 & 23.00 & 12.5545 & 6.09340 \\
\hline \multicolumn{6}{|c|}{ Ten Item Personality Inventory (TIPI) } \\
\hline Extraversion & 101 & 2.00 & 14.00 & 7.7426 & 2.51656 \\
\hline Conscientiousness & 101 & 3.00 & 14.00 & 10.9802 & 2.63811 \\
\hline Agreeableness & 101 & 7.00 & 14.00 & 11.0198 & 2.26265 \\
\hline Neuroticism & 101 & 2.00 & 14.00 & 8.2376 & 2.66889 \\
\hline $\begin{array}{l}\text { Openness to } \\
\text { experience }\end{array}$ & 101 & 2.00 & 14.00 & 8.6634 & 3.04394 \\
\hline \multicolumn{6}{|c|}{ Personal Wellbeing Inventory (PWI) } \\
\hline $\begin{array}{l}\text { Satisfaction with } \\
\text { life as a whole }\end{array}$ & 101 & 16.00 & 90.00 & 57.1584 & 15.55039 \\
\hline
\end{tabular}

Notes: DASS42: 42 items. Scale: $[0]=$ never, $[1]=$ sometimes; [2]= often; [3]= almost always; LOT-R: 10 items. Scale; [0]= strongly disagree, $[\mathrm{I}]=$ disagree, [3]= neutral, [4]= agree, [5]= strongly agree; TIPI: 10 items. Scale: [I]= disagree strongly, [2]= disagree moderately, [3]= disagree a little, [4]= neither agree nor disagree, [5] $=$ agree a little, [6]= agree moderately, [7]= agree strongly; PWI: Presently, using the "satisfaction with life as a whole" subscale, a 10 point Likert scale from [0]= no satisfaction at all, to $[10]=$ completely satisfied.

the lockdown, respectively (Table 4). To the question "Do you think that the intensity and duration of your pain would have been different, if the pandemic hadn't occurred?" (3 conditions: (1) they would be better, (2) they would be the same, (3) they would be worse) significant differences were found with one-way between subjects ANOVA in stress $[\mathrm{F}(2,98)=8.878, \mathrm{p}=0.001]$ and anxiety levels $[\mathrm{F}(2,98)=3.100, \mathrm{p}=0.049]$ as well as in intellect/openness $[F(2,98)=3.644, p=0.030]$. After the application of Bonferroni criterion, the difference in stress was significant between those that answered that they 
Table 4 Patients' Responses to the Perceived Effect of the Pandemic and Lockdown on Access to Healthcare, Pain and Quality of Life

\begin{tabular}{|c|c|c|}
\hline & $\mathbf{N}=|\mathbf{0}|$ & $\%$ \\
\hline \multicolumn{3}{|c|}{ How did the pandemic affect your treatment in general? } \\
\hline Negatively & 41 & 40.6 \\
\hline Not at all & 53 & 52.5 \\
\hline Positively & 7 & 6.9 \\
\hline \multicolumn{3}{|c|}{$\begin{array}{l}\text { Has the number of visits to the Pain Clinic increased or decreased? (either } \\
\text { regular visits or phone contact) }\end{array}$} \\
\hline My visits have decreased & 61 & 60.4 \\
\hline My visits have increased & 3 & 3.0 \\
\hline My visits have remained the same & 37 & 36.6 \\
\hline \multicolumn{3}{|c|}{$\begin{array}{l}\text { Have you reduced your visits to other health care services during the } \\
\text { pandemic? }\end{array}$} \\
\hline A lot & 52 & 51.5 \\
\hline Moderately & 21 & 20.8 \\
\hline Not at all & 28 & 27.7 \\
\hline \multicolumn{3}{|c|}{ To what extent did the Covid-19 pandemic affect your pain levels? } \\
\hline A lot & 12 & 11.9 \\
\hline Moderately & 22 & 21.8 \\
\hline Not at all & 67 & 66.3 \\
\hline
\end{tabular}

To what extent did the restrictive measures (lockdown) affect your pain levels?

\begin{tabular}{|l|l|l|}
\hline A lot & 16 & 15.8 \\
Moderately & 25 & 24.8 \\
Not at all & 60 & 59.4 \\
\hline
\end{tabular}

Do you think that the intensity and duration of your pain would have been different, if the pandemic had not occurred?

\begin{tabular}{|l|c|c|}
\hline They would be better & 24 & 23.8 \\
They would be the same & 71 & 70.3 \\
They would be worse & 6 & 5.9 \\
\hline
\end{tabular}

Do you think that the intensity and duration of your pain would have been different, if the lockdown had not been implemented?

\begin{tabular}{|l|c|c|}
\hline They would be better & 26 & 25.7 \\
They would be the same & 67 & 66.3 \\
They would be worse & 8 & 7.9 \\
\hline To what extent did the pandemic affect your quality of life? \\
\hline A lot & 36 & 35.6 \\
Moderately & 39 & 38.6 \\
Not at all & 26 & 25.7 \\
\hline To what extent did the restrictive measures (lockdown) affect your quality of \\
life? & 38 & 37.6 \\
\hline A lot & 43 & 42.6 \\
Moderately & 20 & 19.8 \\
Not at all & 38 \\
\hline
\end{tabular}

would be better $(\mathrm{M}=23.1, \mathrm{SD}=12.8)$, with those that answered they would be the same (M=13.1, $\mathrm{SD}=9.9)$ (mean difference $=9.956 \mathrm{p}=0.001$ ) and in anxiety between those that answered that they would be better $(M=13.3$, $\mathrm{SD}=11.3$ ) with those that answered they would be the same $\quad(M=8.1, \quad S D=7.9) \quad$ (mean difference $=5.150$, $\mathrm{p}=0.043$ ). In intellect/openness, significant differences were observed between patients that would be better $(\mathrm{M}=8.5 \mathrm{SD}=2.9)$ and those that would be worse $(\mathrm{M}=11.9, \mathrm{SD}=1.9)$ (mean difference $=-3.333, \mathrm{p}=0.047)$.

Regarding the question "Do you think that the intensity and duration of your pain would have been different, if the lockdown hadn't been implemented?" significant results were observed after the one-way between subjects ANOVA, regarding stress $[\mathrm{F}(2,98)=9.783, \mathrm{p}=0.001]$ and anxiety levels $[\mathrm{F}(2,98)=3.754, \mathrm{p}=0.027]$ as well as in intellect/openness $[F(2,98)=6.211, p=0.001]$ and satisfaction with life $[\mathrm{F}(2,98)=3.123, \mathrm{p}=0.048]$. After the application of Bonferroni criterion, the difference in stress was significant between those that answered that they would be better $(\mathrm{M}=24.1, \mathrm{SD}=11.4)$, than with those that answered they would be the same $(M=13.1, \mathrm{SD}=10.9)$ (mean difference $=10.978, p=0.001)$ and in anxiety between those that answered that they would be better $(\mathrm{M}=13.5, \mathrm{SD}=9.9)$ with those that answered they would be the same $(\mathrm{M}=8.1, \mathrm{SD}=8.5$ ) (mean difference $=5.365, \mathrm{p}=0.027$ ). In intellect/openness, significant differences were found between those that would be better $(\mathrm{M}=8.3, \mathrm{SD}=2.8)$ and those that would be worse $(\mathrm{M}=12.1, \mathrm{SD}=2.1)$ (mean difference $=-3.817, \mathrm{p}=0.005$ ), while no significant differences were found in satisfaction with life.

\section{Quality of Life}

Regarding the question "Did the pandemic affect your quality of life", it was evident that most participants' quality of life was affected either significantly (35.6\%), or moderately (38.6\%). Respectively, when asked whether the restrictive measures (lockdown) affected their quality of life, $37.6 \%$ of patients answered "significantly" and $42.6 \%$ of patients answered "moderately" (Table 3). To reveal the differences between the extent that the pandemic affected the quality of life of the patients and the variables of stress, anxiety, depression, optimism, satisfaction with life, and personality, one way of variance ANOVA revealed significant differences in stress $[\mathrm{F}$ 
$(2,98)=4.755, \quad \mathrm{p}=0.011]$ and anxiety $[\mathrm{F}(2,98)=4.590$, $\mathrm{p}=0.012]$. Results after the application of Bonferroni criterion show that there was significant difference in stress levels of those that had been affected a lot by the pandemic $(\mathrm{M}=20.3, \mathrm{SD}=11.7)$ and those that had not been affected at all $(\mathrm{M}=11.6, \mathrm{SD}=10.4)$ (mean difference $=8.728, \mathrm{p}=0.010)$. The same results were revealed in anxiety between those that had been affected a lot by the pandemic and those that had not been affected at all (mean difference $=6.589$, $\mathrm{p}=0.011$ ).

Regarding the question "To what extent did the restrictive measures (lockdown) affect your quality of life?", significant differences were found with one-way between subjects ANOVA $[\mathrm{F}(2,98)=3.474, \mathrm{p}=0.035]$ after the application of the Bonferroni criterion only in stress levels of the patients that their quality of life had been affected a lot $(\mathrm{M}=19.9, \mathrm{SD}=11.1)$ with those that had been affected moderately $(\mathrm{M}=13.7, \mathrm{SD}=11.9)$ (mean difference $=6.173$, $\mathrm{p}=0.05)$.

\section{Medication Use and Pain Symptoms}

$23.8 \%$ of the participants developed a new pain symptom during the pandemic, mostly (70\%) musculoskeletal pain. $32.7 \%$ of the participants had to increase the use of analgesics or switch to a different treatment, due to augmented pain levels perceived as ineffectiveness of the medication. More precisely, regarding the question "Did you have to increase your intake of analgesics, or switch to different medications, because your pain was not subsiding with your current treatment?" results after the application of the independent sample $t$-test revealed that there were significant differences in stress levels $(t=2670, p=0.009)$ between those who found their treatment ineffective and increased their analgesic intake or switched to different medication $(\mathrm{M}=20.4, \mathrm{SD}=12.2)$ and those who did not $(\mathrm{M}=13.9, \mathrm{SD}=10.9)$. The first group had also a lower level of satisfaction $(\mathrm{t}=-2.011, \mathrm{p}=0.04)$ with $(\mathrm{M}=52.8$, $\mathrm{SD}=15.4)$ for the first group and $(\mathrm{M}=59.3, \mathrm{SD}=15.3)$ for the second group, respectively.

\section{Discussion}

This study was conducted during the first wave of the pandemic. This is indicative of the early psychological sequelae of the pandemic outbreak and subsequent restrictions on movement and social interactions. Most of the participants were more worried about their wellbeing, and especially the wellbeing of their loved ones, than about access to healthcare and medication. Level, intensity, and
Table 5 Patients' Responses to Their Personal Experiences with and Expectation of Risk from Covid-19

\begin{tabular}{|l|c|c|}
\hline \multicolumn{2}{|l|}{ N=101 } & $\%$ \\
\hline \multicolumn{2}{|c|}{ Have you been tested positive for Covid-19? } \\
\hline Yes & 0 & 0 \\
No & 92 & 91.1 \\
I do not know & 9 & 8.9 \\
\hline
\end{tabular}

Has anyone you know, relative or acquaintance, been tested positive for Covid-19?

\begin{tabular}{|l|c|c|}
\hline Yes & 8 & 7.9 \\
No & 84 & 83.2 \\
I do not know & 9 & 8.9 \\
\hline
\end{tabular}

Have you lost anyone close to you from Covid-19?

\begin{tabular}{|l|c|c|}
\hline Yes & 3 & 3.0 \\
No & 97 & 96.0 \\
I do not know & 1 & 1.0 \\
\hline
\end{tabular}

Do you belong to a high risk group for Covid-19?

\begin{tabular}{|l|c|c|}
\hline Yes & 49 & 48.5 \\
No & 42 & 41.6 \\
I do not know & 10 & 9.9 \\
\hline
\end{tabular}

Does anyone close to you belong to a high risk group?

\begin{tabular}{|l|c|c|}
\hline Yes & 66 & 65.3 \\
No & 31 & 30.7 \\
I do not know & 4 & 4.0 \\
\hline
\end{tabular}

duration of pain were not directly affected, in contrast with quality of life, which was moderately or significantly affected in most cases.

None of the participants had been sick with coronavirus, a very small number had an acquaintance or relative that had contracted Covid-19, and only 3 had lost a loved one to the disease. Nevertheless, half of the participants believed that they belonged to a risk group and $65 \%$ had or believed they had at least one close family member that belonged to a risk group (Table 5). This number is justified both by the mean age of our sample and by the high prevalence of pain conditions among caregivers. ${ }^{33,34}$ The intensity of people's fear for their wellbeing and especially for their loved ones was not revealed in the questionnaires as much but was sharply evident during the phone interviews. Many of the participants were indeed caregivers of a disabled child or sibling, a spouse, or an elder parent.

There was a significant decrease in health care visits. Adding to the 42-day shutdown of all healthcare outpatient 
services, fear was an important factor. Since "Attikon" became a Covid-19 Reference Hospital, many patients cancelled their existing appointments due to fear of infection, even before or long after the lockdown. However, most patients did not feel that access to pain physicians and medication were significantly affected: they still felt they would be able to reach the doctors via phone if they wished, and that they would have ongoing access to medication.

For most, the level of pain was not affected by the pandemic and was affected only slightly by the lockdown. Only a few patients believed that the intensity and duration of their pain would have been better if it was not for the pandemic or the lockdown - a highly hypothetical question, designed to assess the subjective experience of pain and the connotations and expectations attached to it.

The most important psychological determinant in our study proved to be stress, as measured with DASS42. High levels of stress were associated significantly with higher pain levels, higher intensity and duration of pain, and increased analgesic intake. Higher anxiety was also associated with higher pain levels and higher intensity and duration of pain, although it did not seem to affect the patients' response to medications. Higher levels of depression, as shown with DASS42, were only associated with higher pain levels due to lockdown. The same applied to higher levels of neuroticism, as measured with TIPI. Neuroticism refers to a tendency to experience negative emotions such as worry, sadness, and anxiety. It is strongly linked to emotional distress, depression, ${ }^{35,36}$ and negative health outcomes. ${ }^{37}$ Our findings underline a consistent link between neuroticism, depression, and pain experience and severity. ${ }^{38-40}$ High levels of depression and neuroticism did differentiate significantly the fraction of patients who believed that their pain levels were affected a lot by the lockdown and the subsequent restriction of movement and social isolation.

Patients with high levels of openness to experience, as measured also with TIPI, were more likely to report that the intensity and duration of their pain would have been better if the pandemic had not occurred, and if the restrictive measures had not been implemented. The personality trait "openness to experience" is associated with a broad spectrum of characteristics, including a need for intellectual and aesthetic stimulation, a need for new and varied experiences, and unfiltered receptivity of stimuli and information. ${ }^{35,41}$ Typically, chronic pain patients display significantly less openness characteristics, especially when mediated by high levels of depression and anxiety. ${ }^{42,43}$ However, the Covid-19 pandemic seemed to affect tremendously people scoring high on the openness scale. The overwhelming and highly restrictive nature of the current situation affected the participants' perception of the intensity and duration of their pain. Recent research links neuroticism and openness to Covid-19 anxiety and the Covid-19 anxiety syndrome, respectively. ${ }^{44}$ This association helps explain our findings that link neuroticism to higher perceived levels of pain and openness to higher perceived intensity and duration of pain.

Approximately $3 / 4$ of the participants agreed that their quality of life had been affected moderately or significantly. The higher the stress and anxiety, the more people's quality of life seemed to be affected by the pandemic. Higher stress levels also differentiated significantly between those whose quality of life had been affected a lot by the lockdown's restrictive measures. A term adjacent to quality of life, "satisfaction with life as a whole" as measured with PWI, was not directly affected by the pandemic. However, lower levels of satisfaction with life were significantly associated with higher intensity and duration of pain, as well as with an increase in medication intake or switch of medication due to ineffectiveness.

One of the key issues that determined the participants' responses was people's reality, or the perception of reality as to what Covid-19 is and how long it is going to last, as well as their living conditions and whether they had ongoing contact with their loved ones or not during the lockdown. Most of the people participating in our study shared their home with more than two family members, meaning that most of them had people to take care of, or people that could take care of them. That was not the case with everyone, though. $26 \%$ of the participants, most of whom were over 65 years old, lived either alone or with a spouse. A significant number of elderly people were denied access to their loved ones due to movement restrictions and/or fear of contacting Covid-19. Apart from the consequent psychological and emotional burden, ${ }^{44-47}$ this imposed isolation also carries serious implications in terms of access to care, in an era that demands access to care needs to be digitalized.

Best practice recommendations for treating chronic pain patients promote telemedicine. ${ }^{48-52}$ Both the necessity and the complications of this process were visible throughout our research. During the recruitment stage, only 34 patients were familiar with and able to use Google Forms. 4 filled in the forms with assistance from 
a family member. The rest of the participants would rather do a phone interview with one of the psychologists of the Clinic $(\mathrm{N}=48)$. The phone interview, designed to last 20 25 minutes, rarely lasted less than 40 minutes. It represented an active, vibrant link to the whole Pain Clinic staff. These simple, focused phone interviews provided patients with a necessary sense of comfort and continuity. ${ }^{53,54}$ Patients would ask for information on appointments, on how and when to reach the doctors, they required assistance for their pain or medication. They would even share news and grievances. Less than half of the participants $(\mathrm{N}=48)$ had used the application for remote prescribing, an initiative the Greek Government took during the lockdown. $33.7 \%$ of the participants had no idea what that was.

This cross-sectional study provides valuable information on the impact of the first wave of the Covid-19 pandemic on patients' perceptions on chronic pain. However, this strength is also its main limitation. This is a descriptive study, results represent a specific point in time and the small sample size should be taken into account. Anonymity could not be fully maintained during the phone interviews $(\mathrm{N}=48)$, and the inherent limitations of self-report measures, including sampling and response bias, bias of honesty and the will to please the interviewer, should also be considered. ${ }^{26,27}$ At the same time, the subjective nature of the phone interviews provided us with a lot of qualitative information (ie the limitations of telemedicine, patient's physical and emotional isolation, the importance of safety and security among others) that provide new ground for future research.

\section{Conclusion}

High levels of stress and anxiety are typically linked to chronic pain. ${ }^{4,55-57}$ Both are considered normal coping responses to stressful situations, provided they are addressed at and cared for promptly. In the existing reality of the Greek population, the effects of the lockdown, restriction of movement, and social isolation were undoubtedly more tangible and detrimental to patients suffering from chronic pain, especially those living in urban areas, than the fear of the pandemic in itself. On the other hand, the fear of the pandemic, of getting infected with Covid-19 and of losing a loved one to the disease, led to more patients self-isolating and cancelling appointments to healthcare services. In addition to that, the introduction of new technologies in managing the care of an ageing population, especially when external help is restricted, seems to be problematic.
Chronic pain patients were affected by the Covid-19 pandemic on multiple levels: (1) the association between chronic pain, older age, and multiple comorbidities increases the risk of Covid-19 infection with serious complications ${ }^{50}$ (2) the shutdown of outpatient care facilities and complementary treatment facilities, such as physiotherapy and psychotherapy, disrupts patients' access to pain management ${ }^{12,48}$ (3) the restriction of movement and physical activity interferes with the patients' pain severity, physical function, and quality of life $\mathrm{f}^{11,47}$ (4) the psychosocial impact of the pandemic among the elderly may include considerable fear, anxiety, irritability, stress, anger, and social withdrawal $^{44,46,58}$ (5) The socio-economic implications of the pandemic are still unknown; however, they already include a reduced workforce, many lost jobs, and fears of impending recessions. ${ }^{59,60}$ This is an added weight to the Greek population who have only just emerged from a decade of recession and a subsequent significant impact on patients' pain levels and quality of life. ${ }^{20}$ Lastly, (6) the long-term pain effects of ICU treatment or secondary diseases and parainfectious pain due to Covid-19 infection are currently under the microscope and remain to be seen. ${ }^{61}$

One year and a significant lockdown period later, with the socio-economic burden of Covid-19 becoming increasingly more felt we will re-visit and re-examine the more subtle findings of this research: the levels of stress and anxiety, a possible up rise to the levels of depression, further psychosomatic pain manifestation, response and adherence to treatment and access to care. Our goal is to identify the problem areas that emerged in chronic pain health care during the Covid-19 pandemic and suggest ways to improve it in the future.

\section{Funding}

This research received no external funding.

\section{Disclosure}

The authors declare that they have no competing interests.

\section{References}

1. Dhama K, Khan S, Tiwari R, et al. Coronavirus Disease 2019-COVID19. Clin Microbiol Rev. 2020;33(4):e00028-20. doi:10.1128/ CMR.00028-20

2. Stawicki SP, Jeanmonod R, Miller AC, et al. The 2019-2020 Novel Coronavirus (Severe Acute Respiratory Syndrome Coronavirus 2) pandemic: a Joint American College of Academic International MedicineWorld Academic Council of Emergency Medicine Multidisciplinary COVID-19 working group consensus paper. J Glob Infect Dis. 2020;12(2):47-93. doi:10.4103/jgid.jgid_86_20 
3. IASP. Unrelieved pain is a global health care problem. Available from: www.iasp-pain.org/files/Content/ContentFolders/ GlobalYearAgainstPain2/20042005RighttoPainRelief/factsheet.pdf. Accessed March 09, 2021.

4. Mills SEE, Nicolson KP, Smith BH. Chronic pain: a review of its epidemiology and associated factors in population-based studies. $\mathrm{Br}$ J Anaesth. 2019;123(2):e273-e283. doi:10.1016/j.bja.2019.03.023

5. Breivik H, Collett B, Ventafridda V, Cohen R, Gallacher D. Survey of chronic pain in Europe: prevalence, impact on daily life, and treatment. Eur J Pain. 2006;10:287-333. doi:10.1016/j.ejpain.2005.06.009

6. Fayaz A, Croft P, Langford RM, Donaldson LJ, Jones GT. Prevalence of chronic pain in the UK: a systematic review and meta-analysis of population studies. BMJ Open. 2016;6:e010364. doi:10.1136/bmjopen-2015-010364

7. Phillips CJ. The cost and burden of chronic pain. Rev Pain. 2009;3 (1):2-5. doi:10.1177/204946370900300102

8. Boersma K, Linton S. Expectancy, fear and pain in the prediction of chronic pain and disability: a prospective analysis. Eur J Pain. 2006;10:551e7103. doi:10.1016/j.ejpain.2005.08.004

9. Lee HJ, Choi EJ, Nahm FS, Yoon IY, Lee PB. Prevalence of unrecognized depression in patients with chronic pain without a history of psychiatric diseases. Korean J Pain. 2018;31:116e24. doi:10.3344/ kjp.2018.31.2.116

10. Rausch Osthoff AK, Niedermann K, Braun J, et al. 2018 EULAR recommendations for physical activity in people with inflammatory arthritis and osteoarthritis. Ann Rheum Dis. 2018;77(9):1251-1260. doi:10.1136/annrheumdis-2018-213585

11. Geneen LJ, Moore RA, Clarke C, Martin D, Colvin LA, Smith BH. Physical activity and exercise for chronic pain in adults: an overview of Cochrane Reviews. Cochrane Database Syst Rev. 2017;1(1):CD011279.

12. Bültzingslöwen I, Eliasson G, Sarvimäki A, Mattsson B, Hjortdahl P. Patients' views on interpersonal continuity in primary care: a sense of security based on four core foundations. Fam Pract. 2006;23 (2):210-219. doi:10.1093/fampra/cmi103

13. Lerman SF, Rudich Z, Brill S, Shalev H, Shahar G. Longitudinal associations between depression, anxiety, pain, and pain-related disability in chronic pain patients. Psychosom Med. 2015;77 (3):333-341. doi:10.1097/PSY.0000000000000158

14. de Heer EW, Gerrits MMJG, Beekman ATF, et al. The association of depression and anxiety with pain: a study from NESDA. PLoS One. 2014;9(10):e106907. doi:10.1371/journal.pone.0106907

15. Tunks ER, Crook J, Weir R. Epidemiology of chronic pain with psychological comorbidity: prevalence, risk, course, and prognosis. Can J Psychiat. 2008;53(4):224-234. doi:10.1177/070674370805300403

16. Dresler T, Caratozzolo S, Guldolf K, et al. Understanding the nature of psychiatric comorbidity in migraine: a systematic review focused on interactions and treatment implications. J Headache Pain. 2019;20 (1):51. doi:10.1186/s10194-019-0988-x

17. Gilam G, Sturgeon JA, You DS, Wasan AD, Darnall BD, Mackey SC. Negative affect-related factors have the strongest association with prescription opioid misuse in a cross-sectional cohort of patients with chronic pain. Pain Med. 2020;21(2):e127-e138. doi:10.1093/pm/pnz249

18. Rogers AH, Kauffman BY, Bakhshaie J, McHugh RK, Ditre JW, Zvolensky MJ. Anxiety sensitivity and opioid misuse among opioid-using adults with chronic pain. Am J Drug Alcohol Abuse. 2019;45(5):470-478. doi:10.1080/00952990.2019.1569670

19. Economou C, Kaitelidou D, Konstantakopoulou O, Vildiridi LV. Policy responses for Greece - Physical infrastructure. Covid-19 health system response monitor - Greece [homepage on the internet]. Available from: www.covid19healthsystem.org/countries/greece/livin ghit.aspx?Section=2.1\%20Physical\%20infrastructure \&Type=Section. Accessed August 15, 2021.

20. Batistaki C, Mavrocordatos P, Smyrnioti ME, et al. Patients' perceptions of chronic pain during the economic crisis: lessons learned from Greece. Pain Physician. 2018;1(21;1):E533-E543. doi:10.36076/ ppj.2018.5.E533
21. Levin PJ, Gebbie EN, Kureshi K. Can the health-care system meet the challenge of pandemic flu? Planning, ethical, and workforce considerations. Public Health Rep. 2007;122:573-578. doi:10.1177/ 003335490712200503

22. Lau A, Chi I, Cummins RA, Lee T, Chou KL, Chung L. The SARS (Severe Acute Respiratory Syndrome) pandemic in Hong Kong: effects on the subjective wellbeing of elderly and younger people. Aging Ment Health. 2008;12(6):746-760. doi:10.1080/ 13607860802380607

23. Song XJ, Xiong DL, Wang ZY, Yang D, Zhou L, Li RC. Pain management during the COVID-19 pandemic in China: lessons learned. Pain Med. 2020;21(7):1319-1323. doi:10.1093/pm/pnaa143

24. Taherdoost H. Sampling methods in research methodology; how to choose a sampling technique for research. Int J Acad Res Manag. 2016;5:18-27.

25. Omair A. Sample size estimation and sampling techniques for selecting a representative sample. SCFHC. 2014;2:142-147.

26. Ranganathan P, Aggarwal R. Study designs: part 1 - an overview and classification. Perspect Clin Res. 2018;9(4):184-186.

27. Setia MS. Methodology series module 3: cross-sectional studies. Indian J Dermatol. 2016;61(3):261-264. doi:10.4103/0019-5154.182410

28. Smyrnioti ME, Lyrakos G, Batistaki C, Kitsou MC, Florou P,

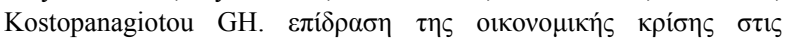

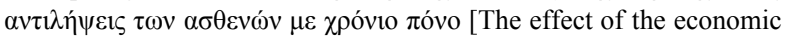
crisis on the perceptions of chronic pain patients]. Presented at: $21 \mathrm{st}$ Panhellenic Congress of Anesthesiology; April 23-26, 2015; Ioannina; Greece.

29. Lyrakos NG, Arvaniti C, Smyrnioti M, Kostopanagiotou G. Translation and validation study of the depression anxiety stress scale in the Greek general population and in a psychiatric patient's sample. Eur Psychiatry. 2011;26:1731. doi:10.1016/S0924-9338(11) 73435-6

30. Lyrakos GN, Papazafiropoulou A, Bousmpoulas S, et al editors. The correlation of the personality in relation to the existence of diabetes mellitus. In: 1 St National Congress of Mental Health in Primary Health Care Proceedings. October 2013; Athens, Greece; 2013:10-13.

31. Lyrakos GN, Damigos D, Mavreas V, Georgia K, Dimoliatis IDK. A translation and validation study of the life orientation test revised in the Greek speaking population of nurses among three hospitals in Athens and Ioannina. Soc Ind Res. 2009;95:129-142. doi:10.1007/ s11205-009-9453-6

32. Hartanty N. Psychometric overview of the personal wellbeing indexadult. In: Cummins R, editor. Personal Wellbeing Index Manual. 6th ed. Deakin University, Melbourne, Australian Centre on Quality of Life, ACQol Open-Access Publications; 2013:xx.

33. Jones SL, Hadjistavropoulos HD, Janzen JA, Hadjistavropoulos T. The relation of pain and caregiver burden in informal older adult caregivers. Pain Med. 2011;12(1):51-58. doi:10.1111/j.15264637.2010.01018.x

34. Hasuo H, Shizuma H, Fukunaga M. Factors associated with chronic thoracic spine and low back pain in caregivers of cancer patients. Ann Palliat Med. 2021;10(2):1224-1236. doi:10.21037/apm-20-803.

35. Costa PT, McCrae RR. The revised neo-personality inventory (NEOPI-R). In: Boyle GJ, Matthews G, Saklofske DH, editors. The Sage Handbook of Personality Theory and Assessment. Vol. 2. Sage Publications; 2008:179-198.

36. Watson D. Neuroticism. In: Smelser NJ, Baltes PB, editors. International Encyclopedia of the Social \& Behavioral Sciences. United Sates: Pergamon; 2001:10609-10612.

37. Smith TW, MacKenzie J. Personality and risk of physical illness. Annu Rev Clin Psychol. 2006;2:435-467. doi:10.1146/annurev. clinpsy.2.022305.095257

38. Payne LA, Seidman LC, Lung KC, Zeltzer LK, Tsao JCI. Relationship of neuroticism and laboratory pain in healthy children: does anxiety sensitivity play a role? Pain. 2013;154(1):103-109. doi:10.1016/j.pain.2012.09.013 
39. Affleck G, Tennen H, Urrows S, Higgins P. Neuroticism and the pain-mood relation in rheumatoid arthritis: insights from a prospective daily study. J Consult Clin Psychol. 1992;60 (1):119-126. doi:10.1037/0022-006X.60.1.119

40. Kadimpati S, Zale EL, Hooten WM, Ditre JW, Warner DO. Correction: associations between neuroticism and depression in relation to catastrophizing and pain-related anxiety in chronic pain patients. PLoS One 2015;10(6):e0129871. doi:10.1371/journal.pone.0129871

41. McCrae RR, Sutin AR. Openness to experience. In: Leary MR, Hoyle RH, editors. Handbook of Individual Differences in Social Behavior. The Guilford Press; 2009:257-273.

42. Ibrahim ME, Weber K, Courvoisier DS, Genevay S. Big five personality traits and disabling chronic low back pain: association with fear-avoidance, anxious and depressive moods. $J$ Pain Res. 2020;13:745-754. doi:10.2147/JPR.S237522

43. Magyar M, Gonda X, Pap D, et al. Decreased openness to experience is associated with migraine-type headaches in subjects with lifetime depression. Front Neurol. 2017;8:270. doi:10.3389/fneur.2017.00270

44. Nikčević AV, Marino C, Kolubinski DC, Leach D, Spada MM. Modelling the contribution of the big five personality traits, health anxiety, and COVID-19 psychological distress to generalised anxiety and depressive symptoms during the COVID-19 pandemic. J Affect Disord. 2021;279:578-584. doi:10.1016/j.jad.2020.10.053

45. Menzies RE, Menzies RG. Death anxiety in the time of COVID-19: theoretical explanations and clinical implications. Cogn Behav Therap. 2020;13:e19. doi:10.1017/S1754470X20000215

46. Khademi F, Moayedi S, Golitaleb M, Karbalaie N. The COVID-19 pandemic and death anxiety in the elderly. Int $J$ Ment Health Nurs. 2020;30(1):346-349. doi:10.1111/inm.12824

47. Karos K, McParland JL, Bunzli S, et al. The social threats of COVID-19 for people with chronic pain. Pain. 2020;161 (10):2229-2235. doi:10.1097/j.pain.0000000000002004

48. Shanthanna H, Strand NH, Provenzano DA, et al. Caring for patients with pain during the COVID-19 pandemic: consensus recommendations from an international expert panel. Anaesthesia. 2020;75 (7):935-944. doi:10.1111/anae.15076

49. Cohen SP, Baber ZB, Buvanendran A, et al. Pain management best practices from multispecialty organizations during the COVID-19 pandemic and public health crises. Pain Med. 2020;21 (7):1331-1346. doi:10.1093/pm/pnaa127
50. Puntillo F, Giglio M, Brienza N, et al. Impact of COVID-19 pandemic on chronic pain management: looking for the best way to deliver care. Best Pract Res Clin Anaesthesiol. 2020;34(3):529-537. doi:10.1016/j.bpa.2020.07.001

51. Li LW, Chew A, Gunasekeran DV. Digital health for patients with chronic pain during the COVID-19 pandemic. $\mathrm{Br} J$ Anaesth. 2020;125(5):657-660. doi:10.1016/j.bja.2020.08.003

52. Eccleston C, Blyth FM, Dear BF, et al. Managing patients with chronic pain during the COVID-19 outbreak: considerations for the rapid introduction of remotely supported (eHealth) pain management services. Pain. 2020;161(5):889-893. doi:10.1097/j.pain.0000000000001885

53. Edwards L, Thomas C, Gregory A, et al. Are people with chronic diseases interested in using telehealth? A cross-sectional postal survey. J Med Internet Res. 2014;16(5):e123. doi:10.2196/jmir.3257

54. Soegaard Ballester JM, Scott MF, Owei L, Neylan C, Hanson CW, Morris JB. Patient preference for time-saving telehealth postoperative visits after routine surgery in an urban setting. Surgery. 2018;163:672-679. doi:10.1016/j.surg.2017.08.015

55. Woo AK. Depression and anxiety in pain. Rev Pain. 2010;4(1):8-12. doi: $10.1177 / 204946371000400103$

56. Blackburn-Munro G, Blackburn-Munro RE. Chronic pain, chronic stress and depression: coincidence or consequence? J Neuroendocrinol. 2001;13(12):1009-1023. doi:10.1046/j.0007-1331.2001.00727.x

57. Timmers I, Quaedflieg C, Hsu C, Heathcote LC, Rovnaghi CR, Simons LE. The interaction between stress and chronic pain through the lens of threat learning. Neurosci Biobehav Rev. 2019;107:641-655. doi:10.1016/j.neubiorev.2019.10.007

58. Dubey S, Biswas P, Ghosh R, et al. Psychosocial impact of COVID-19. Diabetes Mabolic Syndr. 2020;14(5):779-788. doi:10.1016/j.dsx.2020.05.035

59. Nicola M, Alsafi Z, Sohrabi C, et al. The socio-economic implications of the coronavirus pandemic (COVID-19): a review. Int J Surg. 2020;78:185-193. doi:10.1016/j.ijsu.2020.04.018

60 . Verikios G. The dynamic effects of infectious disease outbreaks: the case of pandemic influenza and human coronavirus. Socio Econ Plan Sci. 2020;71:100898. doi:10.1016/j.seps.2020.100898

61. Meyer-Frießem CH, Gierthmühlen J, Baron R, et al. Pain during and after COVID-19 in Germany and worldwide: a narrative review of current knowledge. Pain Rep. 2021;6(1):e893. doi:10.1097/ PR9.0000000000000893
Journal of Pain Research

\section{Publish your work in this journal}

The Journal of Pain Research is an international, peer reviewed, open access, online journal that welcomes laboratory and clinical findings in the fields of pain research and the prevention and management of pain. Original research, reviews, symposium reports, hypothesis formation and commentaries are all considered for publication. The manuscript

Submit your manuscript here: https://www.dovepress.com/journal-of-pain-research-journal management system is completely online and includes a very quick and fair peer-review system, which is all easy to use. Visit http:// www.dovepress.com/testimonials.php to read real quotes from published authors. 